Genealogías del disenso luminoso. Interrupciones escópicas en la fotografía argentina Ana Contursi

Boletín de Arte (N. ${ }^{\circ}$ 19), e013, septiembre 2019. ISSN 2314-2502

https://doi.org/10.24215/23142502e013

http://papelcosido.fba.unlp.edu.ar/ojs/index.php/boa

Facultad de Bellas Artes. Universidad Nacional de La Plata

La Plata. Buenos Aires. Argentina

\title{
GENEALOGÍAS DEL DISENSO LUMINOSO \\ INTERRUPCIONES ESCÓPICAS EN LA FOTOGRAFÍA ARGENTINA
}

\section{GENEALOGIES OF LUMINOUS DISSENT \\ SCOPIC INTERRUPTIONS IN ARGENTINE PHOTOGRAPHY \\ Ana Contursi \\ ana_contursi@yahoo.com.ar}

Laboratorio de Investigación en Prácticas Artísticas y Modos de Acción Política en América Latina. Facultad de Bellas Artes / Centro de Estudios en Filosofía. Facultad de Humanidades y Ciencias de la Educación. Universidad Nacional de La Plata. Argentina

Recibido: 8/2/2019

\section{RESUMEN}

Se propone el trazado de una genealogía para la fotografía contemporánea y colectiva. Se establecen tres coordenadas que dibujan un itinerario significativo en la transformación de los regímenes escópicos argentinos: fotografías del siglo XIX producidas en función de géneros hegemónicos vinculados a la estabilización de la foto como medio de representación de la cultura dominante y de la construcción de una identidad nacional mirando hacia afuera; la emergencia, en las primeras décadas del siglo XX, de prácticas fotográficas disensuales respecto de ese enclave; y el desarrollo contemporáneo de la fotografía colectiva como (re)aparición y fortalecimiento de algunos de los elementos que pueden considerarse como la evidencia histórica de una forma de producir fotografía desde la resistencia (inter)subjetiva, el disenso político y el despliegue de identidades anti statu quo.

Palabras clave

Fotografía; disenso; genealogía; identidades; interrupción

\section{ABSTRACT}

The tracing of a genealogy for contemporary and collective photography is proposed here. Three coordinates that draw a significant itinerary in the transformation of the Argentine scopic regimes are established: photographs of the nineteenth century produced in terms of hegemonic genres linked to the stabilization of the photo as a means of representing the dominant culture and the construction of a national identity looking outward; the emergence, in the first decades of the twentieth century, of dissenting photographic practices with respect to that enclave; and the contemporary development of collective photography as (re)emergence and strengthening of some of the elements that can be considered as the historical evidence of a way of producing photography from (inter)subjective resistance, political dissent and the deployment of identity anti stotu quo.

\section{KEYWORDS}

Photography; dissent; genealogy; identity; interruption 
«El cronista que narra los acontecimientos sin distinguir los grandes de los pequeños da cuenta de la siguiente verdad: la historia no pierde nada de lo que alguna vez aconteció. Por cierto, solo a la humanidad redimida le corresponde su pasado.» Walter Benjamin [1940] (2009)

En consonancia con aquel Friedrich Nietzsche que decía: «Necesitamos la Historia, pero la necesitamos de otra manera de como la necesita el ocioso paseante en el jardín del saber» (en Benjamin, 2009, p. 150), se adhiere aquí al estilo y al procedimiento de una suerte de historiografía de los anocronismos, emprendida para la fotografía argentina hace unos años por Valeria González (2011) en Fotografía argentino. 1840-2010. En esta obra se hablan entre sí imágenes tan distantes y tan próximas como las de Marcos López y de Francisco Ayerza, o las de Adriana Bustos y de Benito Panunzi, o las de Esteban Pastorino y de Fernando Paillet; se hace caso omiso a las exigencias de una cronología histórica lineal y se apuesta a conexiones significativas y saltos elocuentes a través del tiempo. ${ }^{1}$ Se trata de asumir el riesgo de adoptar una metodología "que conecta sin formar sistema y se despliega, hasta el infinito, como un collage que no atiende a los imperativos del tiempo y del espacio. Todo tendrá que ver con todo y eso lo dicta el montaje» (Isola, 2015, p. 168). El legado de Aby Warburg y su Atlas (2010) como un artefacto cartográfico para evocar analogías insospechadas entre imágenes es la base de este atrevimiento gnoseológico.

Martin Jay (2003) señaló, por su parte, que un «régimen escópico» (p. 222) comprende la relación entre un momento histórico particular y sus circunstancias sociales con aquello que se nos hace verosímil visualmente. Luego desarrolló un poco más esta idea y trató de realizar una clasificación no muy exhaustiva de algunas de sus formas en la historia del arte. ${ }^{2}$ Según él, las dinámicas escópicas tienen que ver con aquellas cosas a las que nos acostumbramos visualmente y que responden, de alguna manera, a la realidad que socialmente construimos. La ciberestética o las imágenes del mundo digital, imposibles de concebirse hace no muchos años, son un ejemplo de esas correspondencias. En un mundo volátil donde predominan lo fugaz, lo precario, lo inestable, la invisibilización del capital que se ha vuelto financiero, es concebible que una imagen tenga existencia inmaterial, es decir, que desde la posición y la experiencia de quien la mira forme parte de un acontecimiento evanescente y pueda quedar al margen de la dimensión corporal o material del entorno inmediato. Aceptamos y asumimos posibles una cantidad de imágenes que son acontecimientos de nuestra capacidad perceptiva contemporánea, de nuestro sensorium colectivo actual. En general y desde el sentido común, resulta verosímil la coincidencia entre lo que se ve y lo que la época considera normal que se vea, así como se asumen impropias o anormales las imágenes que escapan a esas catalogaciones de la opinión, el gusto, la ideología y la experiencia hegemónicas de la época.

Puede advertirse que esta tensión entre lo que en un régimen escópico se despliega como normal o anormal es una parte medular de las dinámicas políticas implicadas en lo que jacques Rancière (2014) Ilama partoge du sensible: las distribuciones históricas de las formas de la experiencia, la dialéctica siempre conflictiva entre lo pensable, lo decible, lo visible, lo tocable, lo mostrable, y Ixs sujetxs y objetos - habilitadxs o no- de esos repartos. En este sentido, un régimen escópico particular tendrá siempre una relación estrecha con dimensiones epistémicas y epistemológicas de la cultura. Lo que es (im)posible, (in)deseable o (in)digno de conocimiento es definido al interior de estas dinámicas. Asimismo, el predominio de lo

1 Este trabajo se enmarca en una perspectiva historiográfica con un fuerte interés filosófico y político que intenta desmarcarse de la lógica del discurso histórico clásico. «Anacronismo» y «montaje» (Didi Huberman, 2011), «constelación», «imagen dialéctica» e «imagen fulgurante» (Benjamin, [1940] 2009) son nociones que, si bien no se trabajan particularmente aquí, guían la mirada. Para otras lecturas y/o un abordaje histórico más general y exhaustivo sobre la SFAA consúltese julieta Pestarino (2014-2016), Verónica Tell (2013), Andrea Cuarterolo (2012) y Juan Gómez (1986).

2 Martin Jay (2003) realiza un recorrido histórico de los regímenes de representación visual que resulta central para la investigación general. 
visual en nuestra época podría resumirse en el dicho popular de ver pora creer: el lugar común moderno dice que si algo o alguien no tiene estatuto de visualidad, no existe. Poder ser vistx es poder ser, poder existir.

Claro que estas máximas son solo el despliegue de una perspectiva dominante y, en ese sentido, son solo una parte de lo real. Es justo admitir que las relaciones entre la imagen y la existencia no son unívocas ni imprescindibles. Basta pensar en el fenómeno de la ceguera. 0 , sin ir más lejos, en la visibilización de diversas problemáticas como una instancia más de su devenir ontológico preexistente y no de su nacimiento. Habrá que asumir, entonces, que porque algo no sea visto o mostrado no quiere decir que no exista. Pero se entiende que el canon perceptivo contemporáneo, con su obsesión por la imagen, asuma la visualidad como un acceso a la existencia. El juego entre aparecer y ocultarse en el paisaje escópico actual y la potencia política de cada caso depende de entramados singulares. Esto es relevante para no caer en el dogmatismo visual, pues hay tantas cosas que forman parte de lo real sin ser vistas que sería muy poco riguroso pensar que solo la imagen otorga entidad.

\section{LA MIRADA COLONIZADA}

En 1840 llega el daguerrotipo al Río de la Plata, apenas seis meses después del anuncio del invento en París. La práctica se volvió rápidamente objeto de negocios y fue pronto monopolizada por quienes ya se dedicaban al arte del retrato. Sabemos que «en 1848, ya operaban en Buenos Aires diez daguerrotipistas, la mayoría de ellos extranjeros itinerantes que instalaban sus galerías en casas de familia o en locales de los alrededores de la Plaza de Mayo» (Cuarterolo, 2007, p. 42). Sin embargo, el alto costo que tenía hizo que en sus primeras dos décadas fuera un lujo reservado a quienes podían pagar [Figura 1].

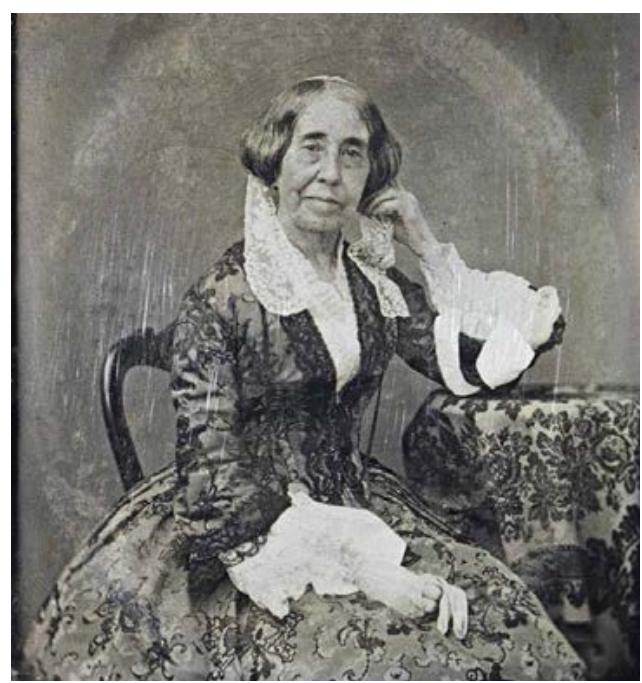

Figura 1. Antonio Pozzo, Doguerrotipo de Mariquito Sánchez de Thompson (1854)(Facio, 1994, p. 11)

No obstante, ya en esa época representó una disminución del costo que había tenido históricamente realizar un retrato pictórico. En ese sentido, podríamos pensar que, aunque no fue revolucionario desde un primer momento, ya estaba prefigurado en su nacimiento el destino popular y democratizador de la fotografía. ${ }^{3}$

3 Si bien existe una polémica en torno de este punto, sostendré la posición explicitada en el texto. A sabiendas de que el efecto democratizador de la fotografía en particular y de la cultura de masas en general ha sido un estandarte publicitario utilizado por el mercado fotográfico (por Kodak, por ejemplo), apuesto a rescatar aquel efecto en el marco de una dialéctica moderna, cuya oscilación va desde la potencia liberada por la democracia como paradigma y los contrapuntos de normalización y de banalización que la industria cultural le impone, al tomar esa potencia como estrategia de mercado. 
Al examinar la situación de la foto en su surgimiento, puede preguntarse por la relación que la misma establece con la tradición iconográfica vigente en el siglo XIX. Si seguimos a Sara Facio (1994), podemos decir que «los retratos fotográficos estaban basados en las mismas pautas estéticas que los óleos» (p. 46). Se utilizaban de una manera generalizada y automática los mismos puntos de vista, modelos, poses y expresiones, lo cual puede observarse en la correspondencia entre el retrato de Mariquita y un óleo europeo y emblemático de la época como puede ser el retrato de la Princesa de Broglie realizado por Ingres a mediados de siglo [Figura 2]. Tanto por cuestiones técnicas - lo costoso del procedimiento- como por razones ideológicas, durante varias décadas se trató de un nuevo modo de representación del estatus, de las prácticas y del pensamiento de las burguesías locales en su afianzamiento identitario posindependentista. Esto no quiere decir que las clases populares no fueran representadas, sino que, si aparecían, lo hacían desde una mirada exotista o de exaltación de las distinciones sociales. Además, el lenguaje propio de la fotografía (la diferencia de planos implicada en la profundidad de campo, el flou, ${ }^{4}$ el corte asimétrico, la visión aérea, el contraste de blancos y negros puros, las gamas de grises, las transparencias, etcétera) no había sido descubierto aún.

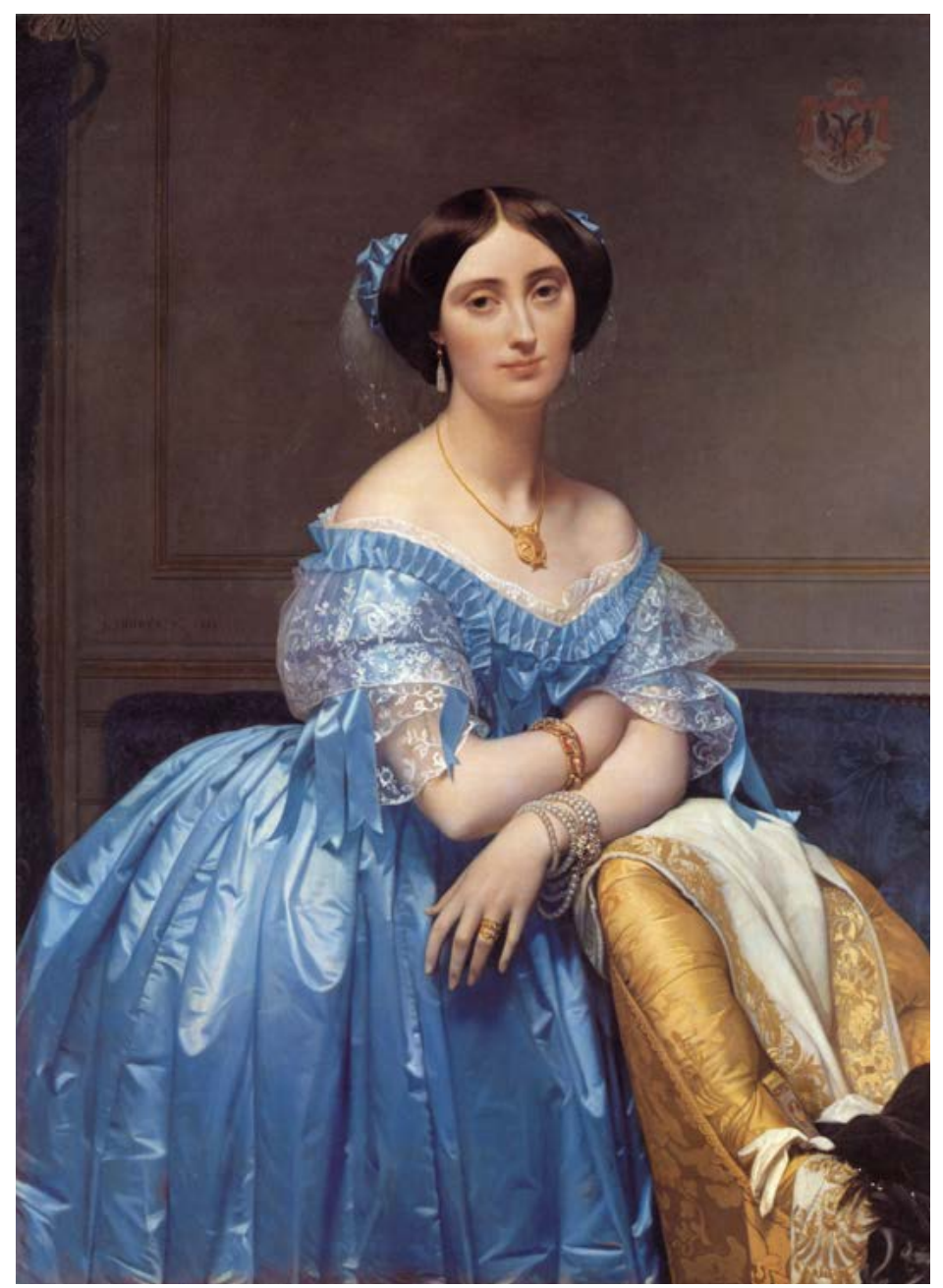

Figura 2. Jean Auguste Dominique Ingres, La princeso de Broglie (1851-1853)

4 Se trata de un procedimiento utilizado por la fotografía pictorialista de las últimas décadas del siglo XIX y las primeras del XX que consiste en aplicar alguna sustancia untuosa sobre la foto al revelarse, sobre el lente o sobre el filtro del mismo, para producir distorsiones en la imagen. El flou es un recurso que busca despegar a la fotografía del anclaje en lo real y acercarla al juego poético y ficcional típico de la pintura, resulta en una disminución de las luces altas que da por resultado colateral una acentuación cromática. 
En este sentido, habrá que admitir que la foto en su primer momento, tanto en Europa como en América, se acopla a las dinámicas de representación de las artes plásticas. Por sus cualidades inherentes, realiza el afán mimético propio del régimen representativo del arte y produce un sismo cultural: no solo le quita la meta de la reproducción fiel del mundo a la pintura, sino que opera una democratización inédita de los modos del aparecer humano y de los modos del aparecer del mundo para la humanidad.

Tras la tendencia hegemónica hacia una mirada colonizada y europeísta (Jauretche, 1967; Dussel, 1996; Zea, 1990; Argumedo, 1993; Mignolo, 1995; Escobar, 1998; Malosetti Costa, 2001; Flores Ballesteros, 2003; De Rueda \& Guzmán, 2018), ${ }^{5}$ representada por demás en ese retrato de Mariquita Sánchez [Figura 1], se prepara una inédita revocación de jerarquías. Son interesantes algunas cuestiones relacionadas con el retrato: en la tradición del siglo XVIII y antes, se trataba de la puesta en imagen de personas embellecidas y exaltadas, únicamente de la nobleza o de la historia bíblica. Durante el siglo XIX, el desarrollo acelerado de la sociedad moderna vinculado estrechamente al surgimiento de la fotografía y a la reproductibilidad técnica, la democratización de la cultura mediante la gráfica, la diversificación urbana y la mirada imperialista, contribuyeron a que se transformaran sus características. Aparece un interés inusitado por los aspectos psicológicos de los personajes retratados, así como se vuelve posible retratar a gentes diversas a modo de escenificación de la proliferación humana, la variedad y las diferencias en un marco global de relaciones asimétricas entre centros y periferias, tanto geográficas como simbólicas. Por una parte, desde tiempos inmemoriales, el retrato se ha usado "para una variedad de propósitos dinásticos, conmemorativos, personales y propagandísticos» (West, 2004, p. 59). El deseo de trascendencia y de memoria ha sido uno de los principales leitmotiv de este género antiquísimo. Por otra parte, una forma adicional de trascendencia liga al retrato con la perpetuación y, de alguna forma, la legitimación del poder. He aquí una de sus funciones políticas más desplegadas en esta tecnología de la autopercepción y la heteropercepción. La mímesis como dispositivo perceptual dominante en la primera mitad del siglo XIX respondió así a exigencias de fidelidad, exactitud y legitimidad. Contrariamente a lo que ocurría con la pintura de inspiración cristiano-feudal en la que la ausencia de fondo representaba una alusión a lo extra material, las dinámicas escópicas que pedía la mentalidad moderna se hacían eco de las exigencias de veracidad y de propiedad material que tenían las burguesías en ascenso o estabilización.

\section{INTERRUPCIONES ESCÓPICAS}

Una de las colecciones de fotografías de Buenos Aires y algunas provincias del interior más importantes de fines del siglo XIX y comienzos del XX es la que pertenece a la Sociedad Fotográfica Argentina de Aficionados (SFAA). El grupo se formó en 1889 bajo el liderazgo del Dr. Francisco Ayerza y al poco tiempo se mudó a la calle Florida. Tras un incendio y algunas mudanzas se estableció en la avenida de Mayo al 800. Participaron de la primera sesión Leonardo Pereyra (presidente), Germán Kühr, Francisco Ayerza (secretario), José María Gutiérrez, Roberto Wernicke, Ricardo N. Murray, Fritz Büsch, Juan Quevedo, Isidro Calderón de la Barca Piñeyro, Daniel Mackinglay, Leonardo Pereyra Iraola, Fernando Steinius y Fernando Denis. A este grupo fundador se incorporaron más tarde otrxs aficionadxs, entre quienes se encontraban algunas personalidades conocidas, como el impresor Jacobo Peuser, el escultor Hernán Cullen Ayerza, Rafael y Marcelino Herrera Vegas, los naturalistas Eduardo Ladislao Holmberg y Clemente Onelli, el crítico José María Lozano Mouján, el coleccionista Alfredo González Garaño, Federico Leloir, Juan A. Montes-Ziegler, Victoria Agui y Gisele Shaw. En 1900 contaba con

5 Se asume como indiscutible esa tendencia hegemónica europeizante de los modelos coloniales y de los países periféricos con historias de colonización, tendencia trabajada por el revisionismo latinoamericano por infinidad de autorxs, lo cual ha permitido la emergencia del paradigma decolonial en estas latitudes en las últimas cinco décadas. Es este paradigma el que nos brinda la base para pensar los intersticios resistentes que se despliegan al interior de esos marcos de dominación cultural. 
alrededor de cien socixs, muchxs de los cuales eran personalidades destacadas en la vida cultural y política de la ciudad (Gómez, 1986; Pestarino, 2014-2016).

Una foto de su archivo llama la atención. Entre lo que podría ser un catálogo de personajes del mundo del trabajo semiurbano de la incipiente Argentina capitalista, un atorrante 0 un linyera aparece en pose, en una clara fotografía de estudio. Frente a la representación algo costumbrista de los tipos productivos, con sus enseres típicos, herramientas de trabajo y el escenario natural o neutro para destacar la actividad [Figura 3], la pose arbitraria y antinatural del atorronte fuera de su contexto propio puede leerse como fuga [Figura 4]. Podría pensarse que el desfile de los personajes de trabajo responde, al igual que las representaciones típicas de indios y gauchos, a una voluntad de exhibir la modernidad en ciernes por estas latitudes (Pestarino, 2014-2016, p. 4). La proliferación de ocupaciones vinculadas a la urbanidad - el cartero, los policías, los canillitas y changarines, el barrendero, etcétera- y a la identidad de economía primaria que Argentina ofrecía al mundo en el momento de su inserción dependiente en el mercado capitalista internacional - los vendedores de fruta, los peones de campo, el pescador, etcétera-, hace que la figura del linyera se descalce de esa puesta en escena generalizada de la productividad. Sujeto improductivo, representante de la falla del sistema, no es ni siquiera mano de obra barata o sujeto histórico salvaje a domesticar. Es un residuo resistente a la modernidad de las buenas costumbres.

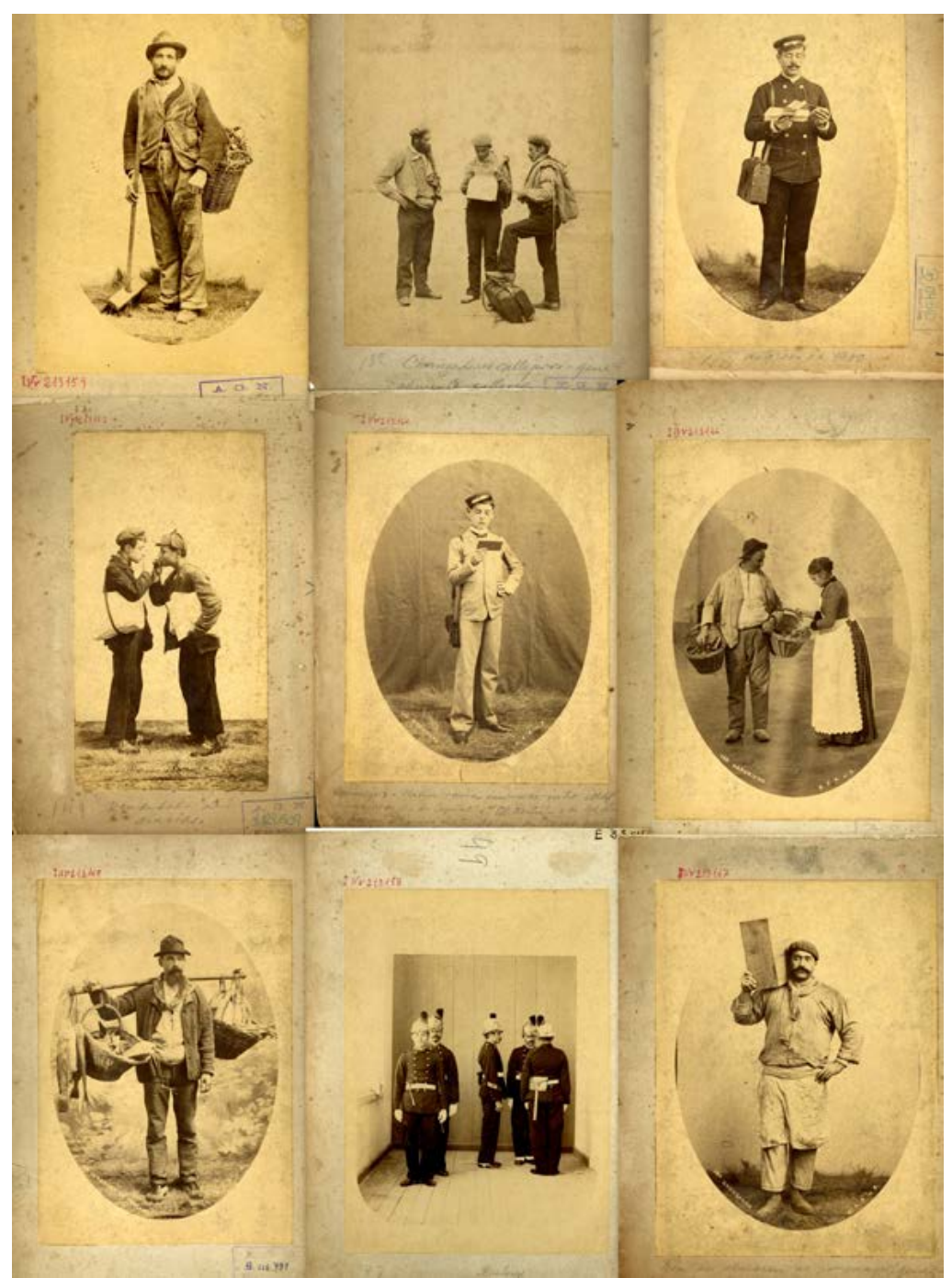

Figura 3. El barrendero, Los changarines, Cartero, Los vendedores de diarios, El mensajero, Naranjero, El vendedor de pescado, Los Policías y El changador (s. f.) 




Figura 4. Un atorrante (s. f.), Anónimo

A esta hipótesis puede sumarse la para nada tímida estetización que muestra la imagen. En una actitud poco discernible, como hurgando en una caja de vinos «Porto» -que reza el año 1867- con un palo del que no se deduce función alguna, el hombre exhibe un brazo arbitrariamente desnudo por detrás del hombro harapiento del primer plano, que porta una bolsa de arpillera. La inverosimilitud de la escena contrasta con la claridad argumental de las demás fotografías, ¿será que tener habitantes linyeras era signo de urbanidad? No obstante, la actitud desafiante del sujeto improductivo, destacada sobre todo en la expresión de su rostro que completa la pose casi principesca, puede leerse más como una impugnación a las necesidades de orden y progreso dominantes en la época que a un guiño de modernidad. Ya había pasado la revolución del régimen estético del arte con las disrupciones y los trastocamientos de la novela y la pintura naturalistas, realistas e impresionistas, movimientos íntimamente ligados al desarrollo de lo fotográfico, tanto desde el punto de vista perceptivo y visual como con relación a los temas. Son los cánones de lo representable los que se ven profundamente transformados, en un movimiento que va de las prácticas artísticas a los imaginarios sociales y políticos. ${ }^{6}$

6 Según Pierre Francastel (1960), el impresionismo da un salto con su espacio aprehensivo, sus encuadres oblicuos y puntos de vista inéditos. La relación con el encuadre fotográfico lleva al uso de fragmentos y de primeros planos; aparece el fragmento como novedad en una concepción analítica que va de lo particular al todo y advierte la dialéctica entre las continuidades y las discontinuidades de los hechos y la historia. El postulado de Rancière (2013) que dice que la revolución social es hija de la revolución estética responde a ello. 
No obstante estos indicios de la actividad del grupo como colectivo de impronta artística, se ha asumido que sus integrantes tenían el proyecto de documentar el desarrollo de su ciudad y país. Estxs pertenecían a la elite y buscaban dejar testimonio tanto de su modernidad como de sus tradiciones (Pestarino, 2014-2016). Fotos costumbristas, retratos del progreso urbano e imágenes de la diversidad y riqueza geográfica y arquitectónica dominan a primera vista en el conjunto de la SFAA. Parece que el género de la fotografía social, ya presente en otros países y cuya temática era común en pintura desde hacía tiempo, en la Argentina se empezó a practicar de manera tardía. Luis Priamo (en Álvarez Plá, 2015), entrevistado acerca de su trabajo sobre la fotografía argentina de la segunda mitad del siglo XIX, sostiene sobre las fotos del período:

Se vendían a personas que buscaban llevarse un recuerdo del país. Otras eran encargadas por el Estado, que quería dar cuenta de la construcción de obras civiles como los medios de transporte, las carreteras, puentes, hospitales, escuelas. [...] Estos profesionales fueron los pioneros de un género fotográfico que tenía sus antecedentes en la pintura y el grabado. Pero estos fotógrafos no tenían ningún tipo de intención artística, su objetivo era puramente documental, ponían el trípode y disparaban, sin más. [...] Nos cuentan cómo una ciudad hecha con cuatro ladrillos se convirtió, en cincuenta años, en una ciudad moderna, proto europea. Esto era una colonia y la idea era borrar eso y barrer a España pero, claro, al mismo tiempo, copiar a Europa, que encarnaba la modernidad (s. p.).

Habrá que concordar con el investigador en casi todo lo que dice; sin embargo, me gustaría discutir la idea de que estos fotógrafos y proto-fotoperiodistas no tenían ningún tipo de intención artística y se ceñían exclusivamente a lo documental. Su vocación por una fotografía que excediera el mero registro y la propaganda queda bastante confirmado por la conformación del grupo - entre la que se cuentan artistas y escritores - y por su actividad —que incluía la realización de concursos y muestras-. Parece pertinente señalar ese exceso en la foto del atorrante. Hay otras imágenes en el archivo que se descalzan de aquella lectura reduccionista y dejan filtrar una mirada poética o desobediente que nada tiene que ver con el documentalismo o con la exaltación de clase, aunque la dominante del conjunto responda a las directrices hegemónicas de las prácticas autorreproductivas de la elite ${ }^{7}$, como sostiene Priamo (en A fondo: Luis Priamo, investigador de fotos antiguas, 16 de enero de 2000) en el siguiente pasaje:

\footnotetext{
En su inicio, y por mucho tiempo, la fotografía puede hablar solo de la vida de las clases altas. Con las clases bajas, la relación es de sometimiento.- ¿A qué se refiere? -Por razones económicas, no acceden a este consumo. Y cuando van a un estudio a sacarse fotos es porque el fotógrafo lo pide para hacer una toma costumbrista, las fotos son forzadas, inauténticas. Porque se ponen sus ropas mejores y posan según las convenciones de las clases altas, en un intento de negar o encubrir su origen de clase. [...] Eso también los obligaba a posar decorativamente. Así empezaron a circular postales incluso de conventillos. Era una tradición que venía de Europa (s. p.).
}

De nuevo, estas ideas parecen hablar de la situación hegemónica y generalizada de la fotografía argentina en su comienzo. Sin embargo, es justo advertir que siempre que hay funcionamientos normalizados y generalizados de las cosas, también se despliegan resistencias e impugnaciones, desvíos, fugas, desacuerdos. Ese linyera fotografiado de manera «inauténtica» por algunx de Ixs fotógrafxs de la SFAA no parece pintoresco, ni veo en él la negación de su origen de clase. Tampoco es sencillo imaginar una razón normalizada para su inclusión en la serie de los tipos populares, llena de personajes prometedores de una Argentina pujante y activa. Otra vez, su «posar decorativamente» puede constituir una interrupción, como la que veía Rancière $(2013,2014)$ en la inmovilidad, en la pasividad, en la falta de proporciones y de expresividad del torso mutilado del Hércules de Belvedere, descrito por Johann Joachim Winckelmann en su Historia del Arte en la Antigüedad (2011). El régimen representativo del arte, cuyo principio rector es la mímesis lograda mediante el uso de las proporciones

7 Para una lectura en esa clave de la práctica y de la producción de la SFAA remitirse al ya citado trabajo de Julieta Pestarino (2014-2016), quien ha desarrollado desde esa perspectiva su tesis de grado en Antropología. 
y el ejercicio de la verosimilitud aristotélica, es aquí desbancado por lo que Rancière llama su «régimen estético», en el que la suspensión de las jerarquías y de las distribuciones clásicas de lo sensible toman la escena.

\section{EL DESPLIEGUE LUMÍNICO DE UN NOSOTRXS}

Antes de pasar a la contemporaneidad, vale posar la mirada en el carácter colectivo de la SFAA. Pudiendo manejarse de la manera convencional de entonces - con un local-estudio comercial que se dedicara a vender sobre todo retratos, pero también paisajes, vistas, escenas costumbristas, gauchescas, imágenes exóticas de nuestros pueblos originarios, un repertorio de vocación documental de una práctica estrechamente vinculada a las relaciones internacionales de carácter colonial, y también poscolonial- quienes integran la Sociedad se agrupan, sacan fotos, hacen concursos, realizan tertulias fotográficas, montan muestras. En el marco del afianzamiento de todo un aparato visual identitario, parte de la invención de un ser nacional (Shumway, 1993), Ixs integrantes de la SFAA eligieron conformar un grupo y desarrollar su práctica fotográfica desde allí, sin destacar ni focalizar la autoría o la mirada personal de cada integrante, en un espacio cooperativo e institucionalmente independiente.

Al revisar algunas de las memorias e imágenes que quedaron de su actividad, se manifiesta más como un club o un colectivo moderno de artistas diversos que formaba parte de la clase adinerada local. El anonimato y esa impronta organizativa podrían ser parte de una manera de responder sin consentimiento a las derivaciones hegemónicas de lo fotográfico. Y si bien puede abonarse la lectura de la SFAA como una clase que representa sus capacidades civilizodas de llevar a un país por la vía del progreso, el desliz estetizante sumado a su modo de organización, podría estar hablándonos de una posibilidad política, íntima y fulgurante -y por ello micropolítica一, de sentar disidencia visual respecto de las narrativas dominantes.

En el contexto general en el que las fotografías tratadas en este texto tienen lugar, me llama la atención una consideración de Jay (2003) que vincula las imágenes con las formas de ver en el seno de un fenómeno amplio -y moderno- de revocación de las jerarquías.

\footnotetext{
El mejor modo de entender el régimen escópico de la modernidad es concebirlo como un terreno en disputa, antes que como un complejo integrado armoniosamente por teorías y prácticas visuales. De hecho, hasta podría caracterizárselo en virtud de una diferenciación de sub culturas visuales, cuya separación nos permitió comprender las múltiples implicaciones de la visión de modos que sólo ahora comenzamos a аргесіаг (pp. 222-223)
}

La modernidad es entendida entonces, siguiendo a Jay, como un terreno de disputas y no como un entramado armonioso. En términos de régimen escópico, la contraparte del despliegue de formas generalizadas de visualidad y pensamiento es un desarrollo siempre latente de formas alternativas, o de interrupciones y disidencias. La genealogía y la arqueología de la fotografía pueden ser vistas en este sentido como una genealogía y una arqueología de las ideas, de los sistemas de pensamiento, de valores y de regímenes escópicos en pugna.

Si acepto la proposición kraussiana de que «la inscripción de la fotografía en el panorama estético contemporáneo se vincula a sus desplazamientos, desdefiniciones y concomitancias con otras artes» (de Rueda, 2010, p. 1), asumo la tensión entre su identidad documental y su ser puesta en escena, composición, sin mayores complicaciones que las que se tienen al querer identificar los ingredientes de realidad y ficción en una pintura moderna. Sabemos con Rancière (2013) que las experiencias artísticas de la llamada modernidad se inscriben en lo que él denomina el régimen estético del arte.

La fotografía, al inscribirse en el panorama estético del arte moderno, no escapa de esta dialéctica y la realiza en su forma más acabada: consigue pegarse por completo a los referentes con los que se relaciona activando una deixis, a la vez que despliega en su praxis como acto (Dubois, 2015) todas las operaciones poéticas que antes eran propias del arte: encuadre, punto 
de vista, manipulación cromática, composición por planos mediante la elección de la profundidad de campo, producción de metáforas y metonimias, puesta en escena en general y demás operaciones de ficcionalización.

Puede verse con claridad el carácter paradójico de lo fotográfico: mientras constituye una reproducción automática del mundo, opera una ficcionalización que habilita nuevas inscripciones de sentido y de sentimiento. Conecta con todo un imaginario - en tanto memoria y archivo de lo visto- en cada caso.

Transcurrido un siglo, en la actualidad existe una fotografía que remite a aquellos enclaves desobedientes de la SFAA. Los colectivos fotográficos contemporáneos están integrados, en general, por fotógrafxs que se reconocen en el trabajo cooperativo, no priorizan la autoría personal, se hacen eco de temas y problemáticas representativas de la época y la coyuntura, pero no se identifican ni con el discurso visual de los medios - el fotoperiodismo clásico- ni con la impronta poética y singular de lxs fotógrafxs artistas. Desarrollan la tarea de poner en escena narrativas alternativas a las que ofrecen los medios masivos, con sus agendas y sus lugares comunes de representación de los conflictos; la autonomía (de tema y de mirada) que permite la no inscripción institucional es uno de los rasgos más fuertes de este tipo de fotografía entre lo informativo y lo artístico. Es una práctica de frontera.

En la fotografía que completa esta genealogía, perteneciente a la serie «El triunfo del Este» del colectivo SADO [Figura 5], despunta una imagen anómala. Conductores de colectivo festejan su victoria sindical frente a la patronal que amenazaba con destruir sus fuentes de trabajo. Los rostros son de alegría en todos, pero en el que es alzado por sus compañeros la expresión es de éxtasis. La felicidad está representada toda junta en ese rostro, la entrega a los brazos de los otros, el relajo de las piernas, el abrazo a quienes lo sostienen. La espontaneidad y la desobediencia de la escena se condensan en esa panza que empuja, abre la camisa y se asoma, triunfante.

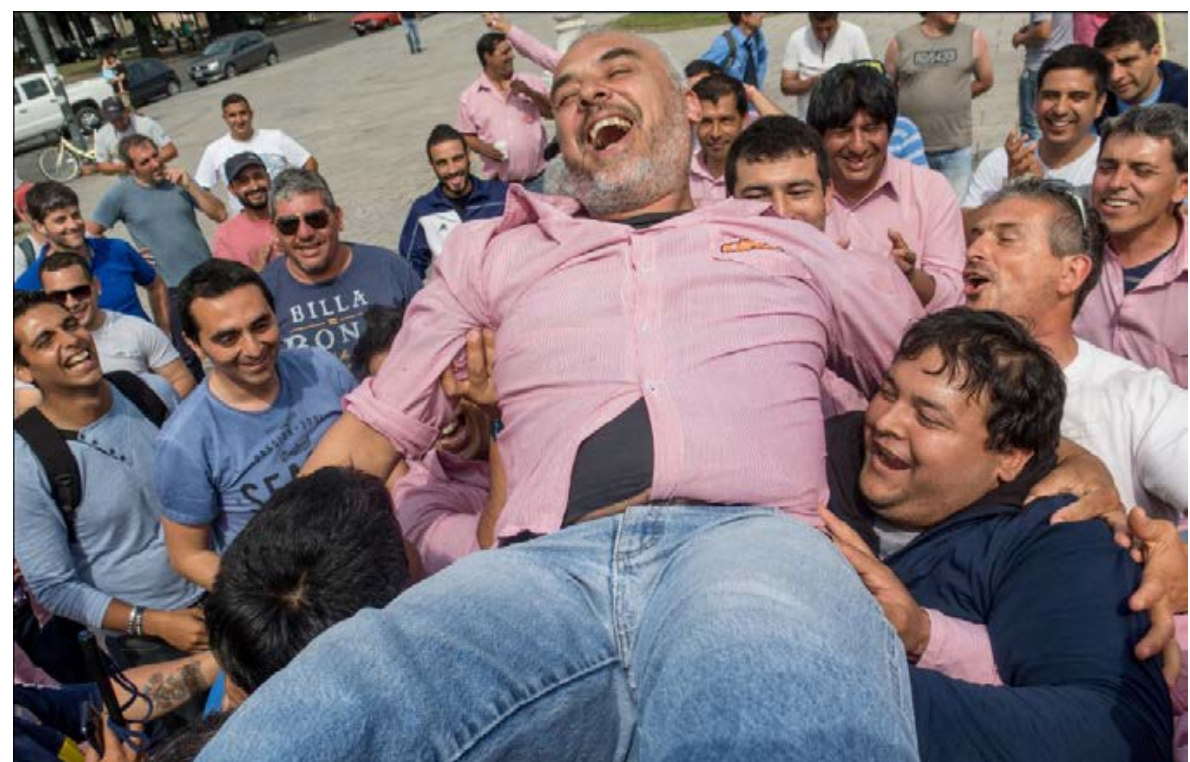

Figura 5. SADO colectivo fotográfico, El triunfo del Este (2017). Imagen cedida por SADO

La representación clásica de Ixs trabajadorxs desde un punto de vista costumbrista, exaltado o miserabilista, es desterrada en esta imagen: ni típicos ni exóticos, ni heroicos ni alienados; de fiesta. Estos trabajadores han vencido en su momento de lucha y de organización -y en el presente eterno de la fotografía - al sistema que quería expulsarlos. Aquel hacerse valer que Gisèle Freund (2006) veía como la función central de la fotografía en su surgimiento moderno, vinculado allí al ascenso de las burguesías y asociado al paradigma liberal y capitalista del 
individualismo es aquí, al igual que en la foto de «El atorrante», invertido. El atorrante fuera de lugar y los trabajadores en su lopsus de felicidad política despliegan, al contrario, todo un imaginario en desacuerdo con los lugares comunes y con los papeles asignados por el statu quo. Una puesta en escena propia del régimen estético y las dinámicas escópicas de sociedades en tránsito, en transformación permanente. Se hace visible la relación de la fotografía con un proceso a contrapelo de las injusticias dominantes del progreso moderno: el de las razones y los afectos populares, el de la potencia de lo colectivo, el del costado emancipatorio de la democracia. Siempre hay un resto que impide que la opresión sea completa, la subjetividad no puede ser aniquilada hasta el punto en que no queden huellas. Y, a su vez, ese resto no puede reducirse a la resistencio contrahegemónica identificada de manera taxativa y categórica.

Como sostenía Alcira Argumedo (1993) en aquel texto fundante de una mirada decolonial, nos hace falta reconocer «la heterogeneidad cultural de los sectores populares de América Latina» (p. 15). Esa heterogeneidad, una vez asumida, manifiesta la imposibilidad del dogma y las miradas totalitarias. La matriz para el desarrollo de un pensamiento y un accionar autónomos para Latinoamérica puede llegar a vincularse con contramovimientos no liberales - el abandono de la ideología del progreso global y occidental cuyo modelo es Europa-, no nacionalistas - con las dificultades que comporta esa mirada para el reconocimiento de la plurinacionalidad latinoamericana-, no aristocratizantes - lejos del medio pelo de las clases dominantes- y no ortodoxos, para permitir, de esta manera, la emergencia de aquella heterogeneidad que es en realidad el signo de una historia que está plagada de singularidades aún no exploradas.

\section{REFERENCIAS}

A fondo: Luis Priamo, investigador de fotos antiguas (16 de enero de 2000). Clarín. Recuperado de http://www.clarin.com/opinion/fotos-revelan-limitadamente-vida-privada_0 r1kQA0oeAFg.html

Álvarez Plá, B. (12 de diciembre de 2015). Luis Priamo, autor de «Buenos Aires. Memoria antigua. Fotografías 1850-1900». Clarín. Recuperado de http://espectaculos.clarin.com/cultura/ priamo-buenos_aires-fotos-1850_1900_0_Bkwn7yYvQx.html

Argumedo, A. (1993). Los silencios y las voces de América Latina. Ciudad Autónoma de Buenos Aires, Argentina: Colihue.

Benjamin, W. (2009). En Estética y política. Ciudad Autónoma de Buenos Aires, Argentina: Las Cuarenta.

Colorado Nates, 0. (julio de 2013). Retrato y fotografía [Entrada de blog]. Recuperado de https://oscarenfotos.com/2013/07/27/retrato-y-fotografia/

Cuarterolo, A. (febrero de 2007). El retrato fotográfico en el siglo XIX. Un espejo de lo mentolidad burguesa. Ponencia presentada en las 15. Jornadas de Reflexión Académica en Diseño y Comunicación «Experiencias y Propuestas en la Construcción del Estilo Pedagógico en Diseño y Comunicación». Facultad de Diseño y Comunicación de la Universidad de Palermo, Ciudad Autónoma de Buenos Aires, Argentina. Recuperado de https://fido.palermo.edu/servicios_dyc/ publicacionesdc/archivos/10_libro.pdf

Cuarterolo, A. (2012). De la foto al fotograma. Relaciones entre cine y fotografía en la Argentino (1840-1933). Montevideo, Uruguay: Centro Municipal de Fotografía de Montevideo.

De Rueda, M. A. (2010). El lugar como ausencia en la fotografía o la imposiblidad del paisaje. Ponencia presentada en las 7. Jornadas Nacionales de Investigación en Arte en Argentina. Facultad de Bellas Artes de la Universidad Nacional de la Plata, La Plata, Argentina. Recuperado de http://sedici.unlp.edu.ar/handle/10915/38640 
De Rueda, M. A. y Guzmán, G. (2018). Modernidad artística y giro decolonial. Arte e Investigoción, (14), 183-190. doi: 10.24215/24691488e014

Didi-Huberman, G. (2011). Ante el tiempo. Historia del arte y anacronismo de las imágenes. Ciudad Autónoma de Buenos Aires, Argentina: Adriana Hidalgo.

Dominique Ingres, J. A. (1851-1853). La princesa de Broglie [Pintura]. Recuperado de https:// www.metmuseum.org/art/collection/search/459106

Dubois, P. (2015). El acto fotográfico y otros ensayos. Ciudad Autónoma de Buenos Aires, Argentina: La Marca.

Dussel, E. (1996). Filosofía de la liberación. Bogotá, Colombia: Nueva América.

Escobar, T. (1998). Las otras modernidades. Notos sobre la modernidad artística en el cono Sur: el coso paraguayo. Recuperado de http://www.esteticas.unam.mx/edartedal/PDF/Queretaro/complets/TicioEscobar.PDF

Facio, S. (1994). La fotografía en la Argentina. De 1840 a nuestros días. Ciudad Autónoma de Buenos Aires, Argentina: La azotea.

Flores Ballesteros, E. (2003). Lo nacional, lo local, lo regional en América Latina: de la modernidad a la globalización y la antiglobalización. Revisto Huellos, (3), 31-44. Recuperado de http:// bdigital.uncu.edu.ar/167

Francastel, P. (1960). Pintura y sociedad. Nacimiento y destrucción del espacio plástico. Ciudad Autónoma de Buenos Aires, Argentina: Emecé.

Freund, G. (2006). Lo fotografía como documento social. Barcelona, España: Gustavo Gili.

Gómez J. (1986). La fotografía en la Argentina. Ciudad Autónoma de Buenos Aires, Argentina: Abadía.

González, V. (2011). Fotografía argentina. 1840-2010. Ciudad Autónoma de Buenos Aires, Argentina: Fundación Alonso y Luz Castillo.

Isola, L. (2015). Aby Warburg. La pervivencia de las imágenes. Chuy. Revisto de Estudios Literarios Latinoamericanos, 2(2), 167-171. Recuperado de http://revistasuntref.com.ar/index. php/chuy/article/view/129/156

Jauretche, A. (1997). El medio pelo en lo sociedad argentina. Apuntes paro una sociología nocional. Ciudad Autónoma de Buenos Aires, Argentina: A. Peña Lillo.

Jay, M. (2003). Compos de fuerzo. Entre la historio intelectual y la crítica cultura. Ciudad Autónoma de Buenos Aires, Argentina: Paidós.

Krauss, R. (1990). Lo fotográfico: Por una teoría de los desplazomientos. Barcelona, España: Gustavo Gili.

Malosetti Costa, L. (2001). Los primeros modernos. Arte y sociedad en Buenos Aires a fines del siglo XIX. Ciudad Autónoma de Buenos Aires, Argentina: FCA.

Mignolo, W. (1995). Occidentalización, imperialismo, globalización: herencias coloniales y teorías postcoloniales. Revisto Iberoamericono, 61(170-171), 27-40. Recuperado de https://revista-iberoamericana.pitt.edu/ojs/index.php/Iberoamericana/article/view/6392 
Pestarino, J. (2014-2016). La imagen fotográfica bajo la mirada antropológica. El caso de lo Sociedad Fotográfica Argentina de Aficionados (Tesis de licenciatura). Recuperado de http:/ / antropologia.filo.uba.ar/sites/antropologia.filo.uba.ar/files/documentos/Pestarino\%20-020 Tesis.pdf

Rancière, J. (2013). Aisthesis. Escenas del régimen estético del arte. Ciudad Autónoma de Buenos Aires, Argentina: Bordes Manantial.

Rancière, J. (2014). El reparto de lo sensible. Política y filosofía. Ciudad Autónoma de Buenos Aires, Argentina: Prometeo.

Shumway, N. (1993). La invención de la Argentina. Historia de una ideo. Ciudad Autónoma de Buenos Aires, Argentina: Emecé.

Tell, V. (2013). Gentlemen, gauchos y modernización. Una lectura del proyecto de la Sociedad Fotográfica Argentina de Aficionados. Coiono, (3) 1-19.

Warburg, A. (2010). Atlos Mnemosyne. Madrid, España: Akal.

West S. (2004). Portraiture, (Kindle Edition). Oxford, Estados Unidos de Norteamérica: Oxford University Press.

Winckelmann J. J. (2011). Historia del arte en la Antigüedad. Madrid, España: Akal.

Zea, L. (1990). Discurso desde la marginación y la barbarie. Ciudad de México, México: Fondo de Cultura Económica. 